\title{
PENERAPAN SISTEM INFORMASI AKADEMIK DENGAN METODE EXTREME PROGRAMMING
}

\author{
Zuhri Halim ${ }^{1}$ \\ ${ }^{1}$ Program Studi Teknik Informatika, Fakultas Teknik Informatika, Universitas Hamka \\ Universitas Muhammadiyah Prof. Dr. HAMKA \\ Jl. Tanah Merdeka No. 6, Kp. Rambutan, Ps. Rebo, Jakarta Timur \\ ${ }^{1}$ zuhri@uhamka.ac.id
}

\begin{abstract}
Abstrak - Teknologi informasi sudah menjadi hal yang sering kita jumpai dalam kehidupan sehari-hari. Kehadiran teknologi informasi sangat membatu seseorang dalam menyebarkan dan menerima informasi. Karena perkembangannya yang begitu pesat saat ini teknologi informasi tidak hanya menjadi media untuk memperoleh informasi, tetapi dapat juga digunakan sebagai alat bantu di dunia akademis. Taman kanakkanak Almadani adalah sebuah lembaga pendidikan yang berada di Desa Bojong Kecamatan Klapanunggal, Kota Bogor. Taman kanak-kanak ini berada bawah naungan yayasan Ihya Almadani. Yang berdiri sejak tahun 2014. TK ini terdiri dari kelompok bermain TK A dan TK B. Berdasarkan wawancara yang dilakukan oleh peneliti, pengelolaan data yang dilakukan oleh pengelola TK Almadani saat ini masih dilakukan dengan cara manual, yaitu masih dicatat dalam buku sehingga sering terjadi masalah pencatatan maupun kehilangan data karena setiap tahun data-data semakin bertambah banyak. Sulitnya melaporkan hasil belajar siswa kepada orang tua menjadi salah satu permasalahan juga karena kebanyakan orang tua dari siswa mereka sibuk untuk bekerja. Metode penelitian yang digunakan dalam perancangan sistem informasi akademik ini menggunakan Extreme Programming. Diharapkan dengan adanya sistem informasi akademik ini dapat membantu pengelola TK almadani untuk mengelola data serta melaporkan hasil belajar dan perkembangan siswa kepada orangtuanya.
\end{abstract}

Kata kunci : Sistem, Laporan, TK, XP

\section{Pendahuluan}

Teknologi informasi sudah menjadi hal yang sering kita jumpai dalam kehidupan sehari-hari. Kehadiran teknologi informasi sangat membatu seseorang dalam menyebarkan dan menerima informasi. Karena perkembangannya yang begitu pesat saat ini teknologi informasi tidak hanya menjadi media untuk memperoleh informasi, tetapi dapat juga digunakan sebagai alat bantu di dunia akademis.(Herliana, 2017)

Pendidikan prasekolah adalah pendidikan yang dapat membantu pertumbuhan dan perkembangan anak diluar lingkungan keluarga, salah satunya adalah Taman KanakKanak (TK) yang merupakan jenjang pendidikan formal pertama untuk anak usia 4-6 tahun.

Taman kanak-kanak Almadani adalah sebuah lembaga pendidikan yang berada di Desa Bojong Kecamatan Klapanunggal, Kota Bogor. Taman kanak-kanak ini berada bawah naungan yayasan Ihya Almadani. Yang berdiri sejak tahun 2014. TK ini terdiri dari kelompok bermain TK A dan TK B. Berdasarkan wawancara yang dilakukan oleh peneliti, pengelolaan data yang dilakukan oleh pengelola TK Almadani saat ini masih dilakukan dengan cara manual, yaitu masih dicatat dalam buku, data yang dikelola berupa data siswa, guru, fasilitas dan keuangan oleh sebab itu sering terjadi masalah pencatatan maupun kehilangan data,tiap tahun ada saja data yang hilang yaitu terjadi 1 sampai 10 kali kehilangan data karena setiap tahun semakin bertambah banyak. Sulitnya melaporkan hasil belajar siswa kepada orang tua menjadi salah satu permasalahan juga karena kebanyakan orang tua dari siswa mereka sibuk untuk bekerja.

Karena itu, penulis mendapatkan solusi untuk membantu mengelola data akademik serta melaporkan hasil belajar anak kepada orang tuanya. Berdasarkan uraian tersebut, maka penulis menyusun skripsi dengan judul "PENERAPAN SISTEM INFORMASI AKADEMIK DENGAN METODE EXTREME PROGRAMMING"

\section{Metodologi Penelitian}

\subsection{Alur Penelitian}

Secara garis besar metodologi penelitian yang dilakukan dan dipaparkan pada makalah ini dijabarkan dalam diagam alur di bawah ini: 


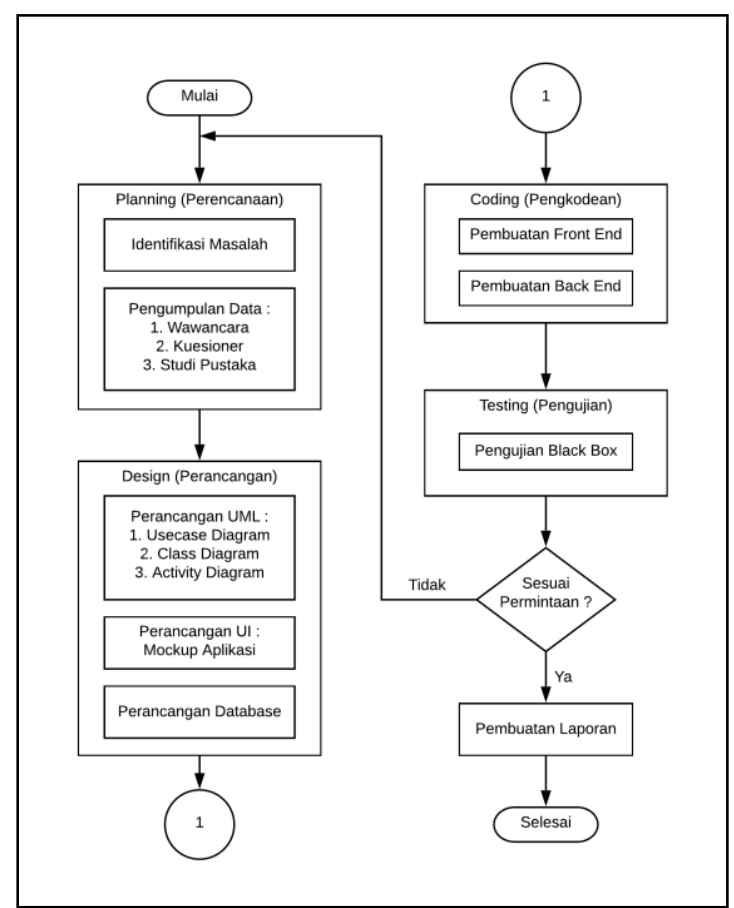

Gambar 1. Diagram Alur Penelitian

Penjelasan untuk tahapan-tahapan dari Extreme Programming adalah sebagai berikut :

A. Planning (Perencanaan)

Tahapan ini adalah tahapan awal ketika membangun suatu sistem pada tahapan ini dilaksanakan beberapa kegiatan perencanaan yaitu, identifikasi masalah, menganalisa kebutuhan dan menetapkan jadwal pelaksaaan ketika membangun sistem.

B. Design (Perancangan)

Tahapan selanjutnya adalah perancangan pada tahap ini

Tahapan berikutnya adalah perancangan pada tahapan ini dilaksanakan kegiatan memodelkan sistem, arsitektur hingga database. Pemodelan sistem dan arsitektur menggunakan diagram Unified Modelling Language (UML) sedangkan pemodelan basis data menggunakan Entity Relationship Diagram (ERD)

C. Coding (Pengkodean)

Tahapan ini merupakan langkah untuk menerapkan pemodelan yang sudah selesai dibuat menjadi bentuk user inteface dengan menggunakan bahasa pemrograman.

D. Testing (Pengujian)

Ketika tahap pengkodean sudah dilakukan, kemudian dilanjutkan dengan tahapan pengujian sistem sehingga dapat menemukan kesalahan-kesalahan yang ada ketika aplikasi sedang berjalan dan dapat mengetahui bahwa sistem yang dibuat sudah sesuai dengan kebutuhan klien.

\subsection{Design (Perancangan)}

A. Perancangan UML

Pada tahapan ini penulis melakukan perancangan fungsional-fungsional UML yang bertujuan untuk melihat sistem yang dimodelkan dari berbagai macam aspek yang berbeda-beda. Jenis-jenis diagram yang penulis gunakan yaitu :

1) Use Case Diagram

2) Class Diagram

3) Activity Diagram

B. Perancangan UI (User Interface)

Pada tahap ini penulis mendesain atau merancang tampilan aplikasi android secara keseluruhan menggunakan teknik Mockup. Penulis membuat tampilan Mockup untuk aplikasi, fungsinya agar klien dapat dengan jelas melihat tampilan hasil desain User interface. Sehingga memudahkan klien dalam menilai apakah desain ini bagus atau tidak dan tata letak fitur-fitur mudah dilihat agar mudah digunakan dan membuat klien tidak mudah bosan dengan tampilan User interface.

D.Perancangan Database

Pada tahap ini penulis melakukan analisis dan penerapan berdasarkan data-data dan juga pemodelan yang telah dilakukan sebelumnya.

\section{Evaluasi Desain Sistem}

Pada tahap ini penulis bertemu dengan pihak-pihak terkait untuk mengevaluasi hasil desain yang telah dibuat sebelumnya, apakah sesuai dengan kebutuhan yang telah ditentukan sebelumnya atau belum, jika belum ulangi lagi proses desain, jika sudah lanjut ketahap selanjutnya.

1. Coding (Pengkodean)

a) Pembuatan Front End

Tahap pembuatan Front End merupakan tahap pengkodean sistem yang bertujuan untuk membuat tampilan aplikasi atau User interface dengan cara mengikuti rancangan Mockup yang sudah ada.

b) Pembuatan Back End

Tahap pembuatan Back End merupakan tahap pengkodean sistem yang bertujuan untuk menjalankan fitur dan fungsi aplikasi yang penulis buat. Dengan cara menerjemahkan perancangan bahasa pemodelan kedalam bahasa pemrograman untuk dapat menjalankan fitur-fitur yang terdapat dalam aplikasi.

c) Testing (Pengujian)

Pada tahap ini sistem yang telah dibuat diuji secara keseluruhan semua fitur-fiturnya. Pengujian dilakukan oleh klien yang nantinya akan di implementasikan sebagai bagian dari software release.

d) Evaluasi Coding (Pengkodean) Sistem

Pada tahap ini penulis mengevaluasi sistem yang sudah dibuat sepenuhnya, baik dari tampilan (User interface) atau dari fungsional sistem aplikasi, apakah sudah memenuhi keinginan dari klien apa belum, jika belum akan dilakukan perbaikan kembali untuk pengkodean sistem aplikasi. 
e) Pembuatan Laporan

Pada tahap ini penulis menjelaskan secara keseluruhan mengenai penelitian yang telah dirancang, dibuat, diuji dan digunakan.

\subsection{Extreme Programming}

Extreme Programming adalah salah satu bentuk proses dari Agile Software Development yang merupakan suatu metodologi dalam pengembangan sistem berbasis Software Development Life Cycle (SDLC). Extreme Programming merupakan metodologi dalam pengembangan sistem dimana berbagai tahapan pada proses pengembangan disederhanakan sehingga suatu proyek pengembangan software dapat lebih efisien dan fleksibel.(Anggraini \& Oliver, 2019).

Extreme Programming merupakan metodologi yang banyak digunakan oleh suatu perusahaan karena penerapan Extreme Programming semuanya dilakukan untuk klien. Tetapi, Anda tidak boleh salah sangka terhadap kata-kata 'programming' yang terdapat dalam Extreme Programming, Extreme Programming tidak hanya berfokus pada source code atau coding, tetapi meliputi seluruh area pengembangan.(Mohammadi et al., 2009)

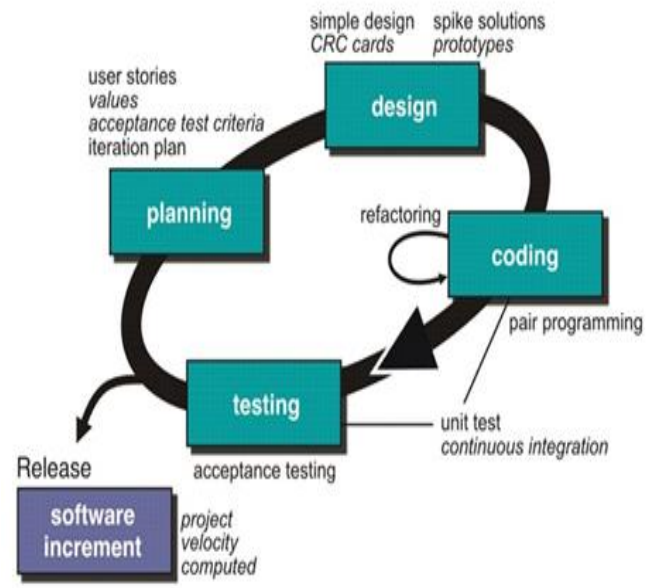

Gambar 2. Konsep Extreme Programming

\section{HASIL DAN PEMBAHASAN}

\subsection{Tahapan Perancangan Sistem}

\subsubsection{Analisis Kebutuhan}

Pada tahap ini dilakukan identifikasi masalah dan analisis terhadap kebutuhan pengguna dan kebutuhan sistem untuk melakukan perancangan sistem. Hasil dari pengolahan dan pengumpulan data kuesioner yang dilakukan oleh penulis dapat diidentifikasikan beberapa masalah serta tingkat presentase kebutuhan pengguna terhadap aplikasi. Sebanyak $68,1 \%$ menjawab bahwa pengelolaan data pada taman kanak-kanak almadani buruk, 70,2\% setuju bahwa sistem yang masih manual pada taman kanak-kanak almadani tidak efektif. Sebanyak $72,3 \%$ setuju bahwa terdapat kendala dalam pengelolaan data sehingga menyebabkan sering terjadi kesalahan dalam pencatatan data serta kehilangan data, $83 \%$ membutuhkan aplikasi sistem informasi akademik. Sebanyak $85,1 \%$ mengiginkan aplikasi yang dibuat berbasis mobile sehingga lebih memudahkan pihak sekolah dan orang tua siswa.

\section{A. Kebutuhan Sistem}

Dalam merancang aplikasi ini agar aplikasi yang dirancang tidak keluar dari rencana awal perancangan aplikasi dibutuhkan batasan-batasan untuk memfokuskan tujuan aplikasi ini dibuat. Kebutuhan sistem yang akan didefiniskan yaitu kebutuhan fungsional dan kebutuhan non fungsional.

Kebutuhan non fungsional adalah menitik beratkan terhadap properti perilaku yang dimiliki oleh sistem, seperti :

1. Sistem yang digunakan harus bersifat User friendly untuk memudahkan User dalam berinteraksi dengan sistem.

2. Sistem keamanan pada sistem Log In Admin sudah dilengkapi dengan menggunakan password_hash dan password_verify.

3. Sistem keamanan pada Log In di dalam aplikasi mobile terutama password sudah dilengkapi dengan menggunakan password_hash.

4. Dibutuhkan koneksi internet yang cepat dan stabil agar sistem dapat berjalan dengan baik.

\section{B. Kebutuhan Fungsional}

Sistem informasi akademik berbasis android pada taman kanak-kanak almadani memiliki kebutuhan fungsional sistem yaitu :

1. Sistem harus dapat memberikan form Log In kepada User, yang terdapat pengisian nomor telepon dan password untuk Log In, serta log out pada aplikasi mobile.

2. Sistem ini memberikan akses kepada Admin, guru, dan orang tua siswa untuk Log In.

3. Sistem ini memberikan pilihan Log In atau log out.

4. Sistem pada Admin adalah web aplikasi yang dapat melakukan penginputan data, pengeditan, meng-update data, penghapusan, dan penyimpanan data.

5. Sistem pada Admin dapat mengelola akun Admin, guru dan akun orang tua siswa.

6. Sistem untuk guru harus dapat memberikan fitur untuk mengelola absen siswa, nilai siswa, kegiatan harian dan perkembangan siswa.

7. Sistem untuk orang tua siswa harus dapat memberikan fitur untuk melihat pengumuman, fasilitas sekolah, absen siswa, nilai siswa, kegiatan harian, perkembangan siswa dan tagihan.

\subsubsection{Rancangan Sistem}


Rancangan sistem untuk aplikasi sistem informasi akademik ini terdiri dari 3 aktor yaitu orang tua siswa, guru dan Admin. Berikut merupakan Use Case diagram dari aplikasi ini

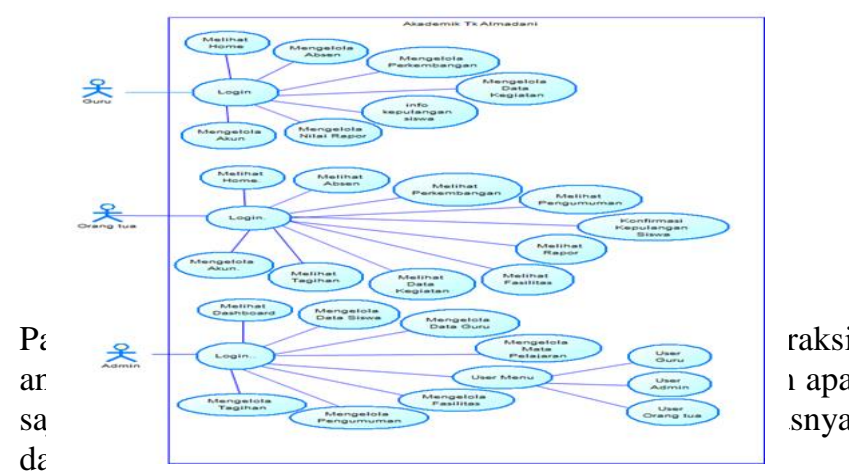

A. $\log$ In $/ \log$ out

Pada tabel 1 di bawah ini menjelaskan tentang spesifikasi alur kerja dari Use Case diagram Log In / log out.

\section{TABEL I}

Deskripsi Use Case Log in / Log Out

\begin{tabular}{|c|c|}
\hline $\begin{array}{l}\text { Nama } \\
\text { Case }\end{array}$ & Log In dan Log out \\
\hline Aktor & $\begin{array}{l}\text { Guru, Orang Tua (User), Admin, } \\
<<\text { service }\rangle>\text { Validasi }\end{array}$ \\
\hline $\begin{array}{l}\text { Deskripsi } \\
\text { singkat }\end{array}$ & $\begin{array}{l}\text { Berfungsi sebagai halaman yang } \\
\text { berisikan formulir login, Admin dan } \\
\text { User yang sudah terdaftar di database } \\
\text { akan memasukan Username dan } \\
\text { password lalu <<service>> validasi } \\
\text { menerima informasi yang dimasukan } \\
\text { oleh Admin untuk mengecek apakah } \\
\text { data yang diinputkan sesuai dengan } \\
\text { yang ada di database, setelah } \\
\text { tervalidasi Admin dapat mengolah } \\
\text { data. }\end{array}$ \\
\hline \multirow[t]{2}{*}{ Tindakan dasar } & $\begin{array}{l}\text { 1. Admin atau User memasukan } \\
\text { nomor telepon dan password. }\end{array}$ \\
\hline & $\begin{array}{l}\text { 2. Setelah selesai melakukan } \\
\text { aktivitas, User dan Admin } \\
\text { melakukan proses log out }\end{array}$ \\
\hline $\begin{array}{l}\text { Alternatif } \\
\text { tindakan }\end{array}$ & Nomor telepon dan password salah. \\
\hline Kondisi awal & $\begin{array}{l}\text { Aktor memasukan nomor telepon dan } \\
\text { password }\end{array}$ \\
\hline Kondisi akhir & $\begin{array}{l}\text { User dan Admin sudah melakukan } \log \\
\text { out }\end{array}$ \\
\hline
\end{tabular}

A. Dashboard
Pada tabel 2 menjelaskan tentang spesifikasi alur kerja dari Use Case diagram Dashboard.

TABEL 2

Deskripsi Use Dashboard

\begin{tabular}{l|l}
\hline $\begin{array}{l}\text { Nama } \\
\text { Case }\end{array}$ & Halaman Dashboard \\
\hline Aktor & Admin \\
\hline Deskripsi & Pada tampilan awal dari selesai Log In,
\end{tabular}
singkat aktor akan dilarikan ke halaman Dashboard, dimana dihalaman ini terdiri dari beberapa tampilan gambar icon dimana icon tersebut mewakili angka dimana setiap data siswa, guru dan mata pelajaran yang masuk maka angka tersebut mengikuti jumlah yang masuk.

\begin{tabular}{l|l}
\hline Tindakan dasar & Pilih menu untuk mengetahui lebih lanjut. \\
\hline Kondisi awal & $\begin{array}{l}\text { Setelah aktor melalui Log In maka akan } \\
\text { membuka web aplikasi. }\end{array}$ \\
\hline Kondisi akhir & $\begin{array}{l}\text { Menampilkan icon-icon yang mewakili } \\
\text { dari setiap menu dari web aplikasi. }\end{array}$ \\
\hline
\end{tabular}

B. Pengolahan Data Siswa

Pada tabel 3 menjelaskan tentang spesifikasi alur kerja dari Use Case diagram mengelola data siswa.

TABEL 3

Deskripsi Use Pengolahan Data Siswa

\begin{tabular}{l|l}
\hline $\begin{array}{l}\text { Nama } \\
\text { Case }\end{array}$ & Data siswa \\
\hline Aktor & Admin \\
\hline $\begin{array}{l}\text { Deskripsi } \\
\text { singkat }\end{array}$ & $\begin{array}{l}\text { Aktor dapat melihat, menambahkan, } \\
\text { merubah, menghapus data siswa }\end{array}$ \\
\hline $\begin{array}{l}\text { Tindakan } \\
\text { dasar }\end{array}$ & $\begin{array}{l}\text { 1. Menampilkan data siswa } \\
\end{array}$ \\
2. Menambahkan data siswa \\
3. Merubah data siswa \\
\hline Kondisi awal & $\begin{array}{l}\text { Setelah melakukan login aktor dapat } \\
\text { memilih menu data siswa }\end{array}$ \\
\hline Kondisi akhir & Menampilkan detail dari data siswa \\
\hline
\end{tabular}

C. Pengolahan Data Guru

Pada tabel 4 menjelaskan tentang spesifikasi alur kerja dari Use Case diagram mengelola data guru.

TABEL 4

Deskripsi Use Pengolahan Data Guru

\begin{tabular}{|l|l|}
\hline $\begin{array}{l}\text { Nama Use } \\
\text { Case }\end{array}$ & Data guru \\
\hline Aktor & Admin \\
\hline Deskripsi & Aktor dapat menampilkan, menambahkan, \\
\hline
\end{tabular}




\begin{tabular}{|l|l|}
\hline singkat & merubah, menghapus data guru \\
\hline Tindakan & 1. Menampilkan data guru \\
dasar & 2. Menambahkan data guru \\
& 3. Merubah data guru \\
& 4. Menghapus data guru \\
\hline Kondisi awal & $\begin{array}{l}\text { Setelah melakukan Log In aktor dapat } \\
\text { memilih menu data guru }\end{array}$ \\
\hline Kondisi akhir & Menampilkan detail dari data guru \\
\hline
\end{tabular}

D. Pengolahan Data Mata Pelajaran

Pada tabel 5 menjelaskan tentang spesifikasi alur kerja dari Use Case diagram mengelola data mata pelajaran

TABEL 5

Deskripsi Use Pengolahan Data Mata Pelajaran

\begin{tabular}{|l|l|}
\hline $\begin{array}{l}\text { Nama Use } \\
\text { Case }\end{array}$ & Data mata pelajaran \\
\hline Aktor & Admin \\
\hline $\begin{array}{l}\text { Deskripsi } \\
\text { singkat }\end{array}$ & $\begin{array}{l}\text { Aktor dapat menampilkan, menambahkan, } \\
\text { merubah, menghapus data mata pelajaran }\end{array}$ \\
\hline $\begin{array}{l}\text { Tindakan } \\
\text { dasar }\end{array}$ & $\begin{array}{l}\text { 1. Menampilkan mata pelajaran } \\
\text { 2. Menambahkan mata pelajaran } \\
\text { 3. Merubah mata pelajaran } \\
\text { 4. Menghapus mata pelajaran }\end{array}$ \\
\hline Kondisi awal & $\begin{array}{l}\text { Setelah melakukan login aktor dapat } \\
\text { memilih menu mata pelajaran }\end{array}$ \\
\hline Kondisi akhir & $\begin{array}{l}\text { Menampilkan data detail dari mata } \\
\text { pelajaran }\end{array}$ \\
\hline
\end{tabular}

E. Pengolahan Data Mata Fasilitas

Pada tabel 6 menjelaskan tentang spesifikasi alur kerja dari Use Case diagram mengelola data fasilitas.

\section{TABEL 6}

Deskripsi Use Pengolahan Data Fasilitas

\begin{tabular}{|c|c|}
\hline $\begin{array}{l}\text { Nama Use } \\
\text { Case }\end{array}$ & Mengelola data fasilitas \\
\hline Aktor & Admin \\
\hline $\begin{array}{l}\text { Deskripsi } \\
\text { singkat }\end{array}$ & $\begin{array}{l}\text { Aktor dapat menampilkan, menambahkan, } \\
\text { merubah, menghapus data fasilitas }\end{array}$ \\
\hline $\begin{array}{l}\text { Tindakan } \\
\text { dasar }\end{array}$ & $\begin{array}{l}\text { 1. Menampilkan data fasilitas } \\
\text { 2. Menambahkan data fasilitas } \\
\text { 3. Merubah data fasilitas } \\
\text { 4. Menghapus data fasiltas }\end{array}$ \\
\hline Kondisi awal & $\begin{array}{l}\text { Setelah melakukan } \log \text { In aktor dapat } \\
\text { memilih menu fasilitas }\end{array}$ \\
\hline Kondisi akhir & Menampilkan data detail dari fasilitas \\
\hline
\end{tabular}

E. Pengolahan Data Pengumuman
Pada tabel 7 menjelaskan tentang spesifikasi alur kerja dari Use Case diagram mengelola data pengumuman.

$$
\text { TABEL } 7
$$

Deskripsi Use Pengolahan Data Pengumuman

\begin{tabular}{|l|l|}
\hline $\begin{array}{l}\text { Nama Use } \\
\text { Case }\end{array}$ & Pengumuman \\
\hline Aktor & Admin \\
\hline $\begin{array}{l}\text { Deskripsi } \\
\text { singkat }\end{array}$ & $\begin{array}{l}\text { Aktor dapat menampilkan, menambahkan, } \\
\text { merubah, menghapus pengumuman }\end{array}$ \\
\hline $\begin{array}{l}\text { Tindakan } \\
\text { dasar }\end{array}$ & $\begin{array}{l}\text { 1. Menampilkan pengumuman } \\
\text { 2. Menambahkan pengumuman }\end{array}$ \\
& $\begin{array}{l}\text { 3. Merubah pengumuman } \\
\text { 4. Menghapus pengumuman }\end{array}$ \\
\hline Kondisi awal & $\begin{array}{l}\text { Setelah melakukan Log In aktor dapat } \\
\text { memilih menu pengumuman }\end{array}$ \\
\hline Kondisi akhir & Menampilkan data detail pengumuman \\
\hline
\end{tabular}

F. Pengolahan Data Tagihan

Pada tabel 8 menjelaskan tentang spesifikasi alur kerja dari Use Case diagram mengelola data tagihan.

TABEL 8

\begin{tabular}{|l|l|}
\multicolumn{3}{|c|}{ Deskripsi Use Pengolahan Data Tagihan } \\
\hline $\begin{array}{l}\text { Nama } \\
\text { Case }\end{array}$ & Data tagihan siswa \\
\hline Aktor & Admin \\
\hline $\begin{array}{l}\text { Deskripsi } \\
\text { singkat }\end{array}$ & $\begin{array}{l}\text { Aktor dapat menampilkan, menambahkan, } \\
\text { merubah, menghapus data tagihan siswa }\end{array}$ \\
\hline $\begin{array}{l}\text { Tindakan } \\
\text { dasar }\end{array}$ & $\begin{array}{l}\text { 1. Menampilkan data tagihan siswa } \\
\text { 2. Menambahkan data tagihan siswa } \\
\text { 3. Merubah data tagihan siswa }\end{array}$ \\
\hline Kondisi awal & $\begin{array}{l}\text { Setelah melakukan Log In aktor dapat } \\
\text { memilih menu data tagihan siswa }\end{array}$ \\
\hline Kondisi akhir & $\begin{array}{l}\text { Menampilkan detail dari data tagihan } \\
\text { siswa }\end{array}$ \\
\hline
\end{tabular}

\section{G. Pengolahan User Menu}

Pada tabel 9 menjelaskan tentang spesifikasi alur kerja dari Use Case diagram mengelola user menu.

$$
\text { TABEL } 9
$$

Deskripsi Use Pengolahan User Menu

\begin{tabular}{|l|l|}
\hline $\begin{array}{l}\text { Nama } \\
\text { Case }\end{array}$ & User Menu \\
\hline Aktor & Admin \\
\hline $\begin{array}{l}\text { Deskripsi } \\
\text { singkat }\end{array}$ & $\begin{array}{l}\text { Aktor dapat menampilkan, menambahkan, } \\
\text { merubah, menghapus didalam data User } \\
\text { Admin, User guru dan User orang tua. }\end{array}$ \\
\hline $\begin{array}{l}\text { Tindakan } \\
\text { dasar }\end{array}$ & $\begin{array}{l}\text { Menampilkan, menambahkan, } \\
\text { merubah, menghapus didalam data } \\
\text { User Admin }\end{array}$ \\
\hline
\end{tabular}




\begin{tabular}{|c|c|}
\hline & $\begin{array}{l}\text { 2. Menampilkan, menambahkan, } \\
\text { merubah, menghapus didalam data } \\
\text { User guru } \\
\text { 3. } \begin{array}{l}\text { Menampilkan, } \\
\text { merubah, menghapus didalam data } \\
\text { User } \text { orang tua }\end{array}\end{array}$ \\
\hline Kond & $\begin{array}{l}\text { Setelah melakukan Log In aktor dapat } \\
\text { memilih menu User Menu }\end{array}$ \\
\hline Kondisi akhir & $\begin{array}{l}\text { Menampilkan data detail dari User Admin, } \\
\text { User guru, User orang tua. }\end{array}$ \\
\hline
\end{tabular}

H. Pengolahan Home

Pada tabel 11 menjelaskan tentang spesifikasi alur kerja dari Use Case diagram mengelola home.

TABEL 11

Deskripsi Use Pengolahan Home

\begin{tabular}{|l|l|}
\hline $\begin{array}{l}\text { Nama } \\
\text { Case }\end{array}$ & Useme \\
\hline Aktor & $\begin{array}{l}\text { Pengguna mobile app (User Guru, User } \\
\text { Orang Tua) }\end{array}$ \\
\hline $\begin{array}{l}\text { Deskripsi } \\
\text { singkat }\end{array}$ & $\begin{array}{l}\text { Pada tampilan awal dari selesai Log In, } \\
\text { aktor akan dilarikan ke halaman home, } \\
\text { dimana dihalaman ini terdiri dari beberapa } \\
\text { tampilan gambar icon dan fitur-fitur yang } \\
\text { ada di dalam aplikasi }\end{array}$ \\
\hline Tindakan dasar & $\begin{array}{l}\text { Menampilkan dan memilih menu yang ada } \\
\text { untuk mengetahui lebih lanjut. }\end{array}$ \\
\hline Kondisi awal & $\begin{array}{l}\text { Setelah aktor melalui Log In maka akan } \\
\text { masuk ke menu home }\end{array}$ \\
\hline Kondisi akhir & $\begin{array}{l}\text { Menampilkan icon-icon yang mewakili } \\
\text { dari setiap menu dari aplikasi }\end{array}$ \\
\hline
\end{tabular}

I. Pengolahan Data Absen

Pada tabel 11 menjelaskan tentang spesifikasi alur kerja dari Use Case diagram mengelola data absen.

TABEL 11

Deskripsi Use Pengolahan Data Absen

\begin{tabular}{|l|l|}
\hline $\begin{array}{l}\text { Nama } \\
\text { Case }\end{array}$ & Ase \\
\hline Aktor & Guru \\
\hline $\begin{array}{l}\text { Deskripsi } \\
\text { singkat }\end{array}$ & Aktor dapat menambah data absensi siswa \\
\hline $\begin{array}{l}\text { Tindakan } \\
\text { dasar }\end{array}$ & $\begin{array}{l}\text { 1. Pilih kelas } \\
\text { 2. Menambahkan data absen siswa }\end{array}$ \\
\hline Kondisi awal & $\begin{array}{l}\text { Setelah melakukan Log In aktor dapat } \\
\text { memilih menu input absen. }\end{array}$ \\
\hline Kondisi akhir & Aktor berhasil menambahkan absen siswa \\
\hline
\end{tabular}

J. Pengolahan Data Akun

Pada tabel 12 menjelaskan tentang spesifikasi alur kerja dari

Use Case diagram mengelola data akun.
TABEL 12

Deskripsi Use Pengolahan Data Akun

\begin{tabular}{|l|l|}
\hline $\begin{array}{l}\text { Nama } \\
\text { Case }\end{array}$ & Akun \\
\hline Aktor & Guru dan orang tua \\
\hline $\begin{array}{l}\text { Deskripsi } \\
\text { singkat }\end{array}$ & $\begin{array}{l}\text { Aktor dapat mengganti nomor telepon dan } \\
\text { password untuk akunnya }\end{array}$ \\
\hline Tindakan dasar & $\begin{array}{l}\text { 1. Pilih menu ganti nomor telepon } \\
\text { 2. Pilih menu ganti password }\end{array}$ \\
\hline Kondisi awal & $\begin{array}{l}\text { Setelah melakukan Log In aktor dapat } \\
\text { memilih menu my account. }\end{array}$ \\
\hline Kondisi akhir & $\begin{array}{l}\text { Aktor berhasil mengganti nomor } \\
\text { telepon/password }\end{array}$ \\
\hline
\end{tabular}

\section{K. Pengolahan Data Nilai Rapor}

Pada tabel 13 menjelaskan tentang spesifikasi alur kerja dari Use Case diagram mengelola data nilai rapor.

TABEL 13

Deskripsi Use Pengolahan Data Nilai Rapor

\begin{tabular}{|l|l|}
\hline $\begin{array}{l}\text { Nama Use } \\
\text { Aase }\end{array}$ & Nilai Rapor \\
\hline $\begin{array}{l}\text { Aktor } \\
\text { singkat }\end{array}$ & $\begin{array}{l}\text { Aktor dapat menampilkan, menambahkan, } \\
\text { merubah, menghapus data nilai raport } \\
\text { siswa berdasarkan mata pelajaran yang } \\
\text { ada }\end{array}$ \\
\hline Tindakan dasar & $\begin{array}{l}\text { 1. Pilih menu input nilai rapor } \\
\text { 2. Pilih kelas } \\
\text { 3. Pilih nama siswa } \\
\text { 4. Input nilai }\end{array}$ \\
\hline Kondisi awal & $\begin{array}{l}\text { Setelah melakukan Log In aktor dapat } \\
\text { memilih input nilai rapor }\end{array}$ \\
\hline Kondisi akhir & Aktor berhasil input nilai rapor siswa \\
\hline
\end{tabular}

\section{Pengolahan Data Kegiatan}

Pada tabel 14 menjelaskan tentang spesifikasi alur kerja dari Use Case diagram mengelola data nilai kegiatan.

TABEL 14

Deskripsi Use Pengolahan Data Kegiatan

\begin{tabular}{|l|l|}
\hline $\begin{array}{l}\text { Nama Use } \\
\text { Case }\end{array}$ & Data Kegiatan \\
\hline Aktor & Guru \\
\hline $\begin{array}{l}\text { Deskripsi } \\
\text { singkat }\end{array}$ & $\begin{array}{l}\text { Aktor dapat menampilkan, menambahkan, } \\
\text { merubah, menghapus data kegiatan harian }\end{array}$ \\
\hline
\end{tabular}




\begin{tabular}{|l|l|}
\hline & siswa sesuai kegiatan yang dilakukan \\
\hline Tindakan dasar & $\begin{array}{l}\text { 1. Pilih menu input kegiatan harian } \\
\end{array}$ \\
& $\begin{array}{l}\text { 2. Pilih kelas } \\
\text { 3. Pilih nama siswa } \\
\text { 4. Input catatan kegiatan harian }\end{array}$ \\
\hline Kondisi awal & $\begin{array}{l}\text { Setelah melakukan Log In aktor dapat } \\
\text { memilih input kegiatan harian }\end{array}$ \\
\hline Kondisi akhir & $\begin{array}{l}\text { Aktor berhasil input catatan kegiatan } \\
\text { harian siswa }\end{array}$ \\
\hline
\end{tabular}

L. Pengolahan Data Perkembangan

Pada tabel 15 menjelaskan tentang spesifikasi alur kerja dari Use Case diagram mengelola data perkembangan.

TABEL 15

Deskripsi Use Pengolahan Data Perkembangan

\begin{tabular}{|l|l|}
\hline $\begin{array}{l}\text { Nama Use } \\
\text { Case }\end{array}$ & Perkembangan \\
\hline Aktor & Orang tua \\
\hline $\begin{array}{l}\text { Deskripsi } \\
\text { singkat }\end{array}$ & $\begin{array}{l}\text { Aktor dapat menampilkan perkembangan } \\
\text { siswa }\end{array}$ \\
\hline Tindakan dasar & $\begin{array}{l}\text { 1. Pilih menu perkembangan } \\
\text { 2. Menampilkan perkembangan } \\
\text { berdasarkan jenis perkembangan }\end{array}$ \\
\hline Kondisi awal & $\begin{array}{l}\text { Setelah melakukan Log In aktor dapat } \\
\text { memilih menu perkembangan }\end{array}$ \\
\hline Kondisi akhir & $\begin{array}{l}\text { Aktor berhasil menampilkan } \\
\text { perkembangan siswa berdasarkan jenisnya }\end{array}$ \\
\hline
\end{tabular}

\subsubsection{Rancangan Prototype}

a. Interface Halaman Login Sistem Informasi TK Almadani

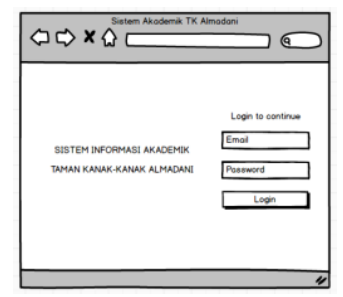

Gambar 3.Rancangan Tampilan Login

b.Interface Dasboard Admin

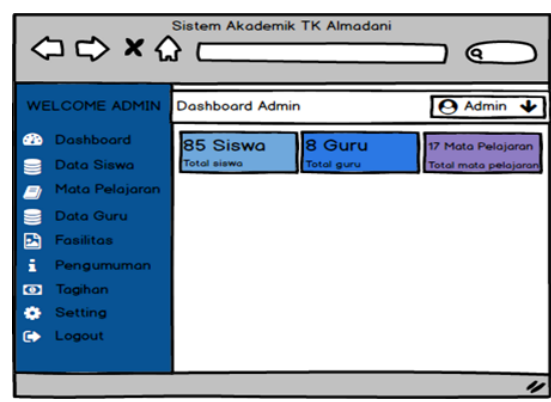

Gambar 4.Rancangan Tampilan Form Dashboard Admin c.Interface Menu Login User

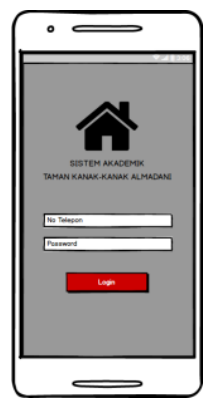

Gambar 5.Rancangan Tampilan Menu Login User

d.Interface Menu Input Nilai Rapor

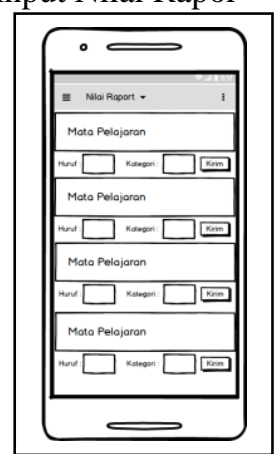

Gambar 5.Rancangan Tampilan Menu Input Nilai Rapor e.Interface Menu Home User Guru

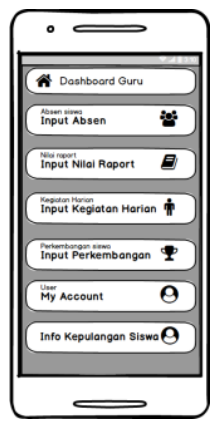

Gambar 6.Rancangan Tampilan Menu Home User Guru 
e.Interface Menu Cek Rapor

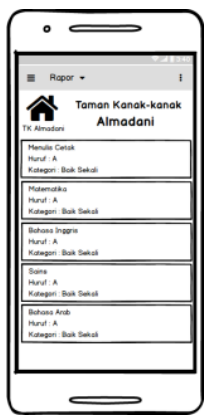

Gambar 7.Rancangan Tampilan Menu Cek Rapor f.Rancangan ERD

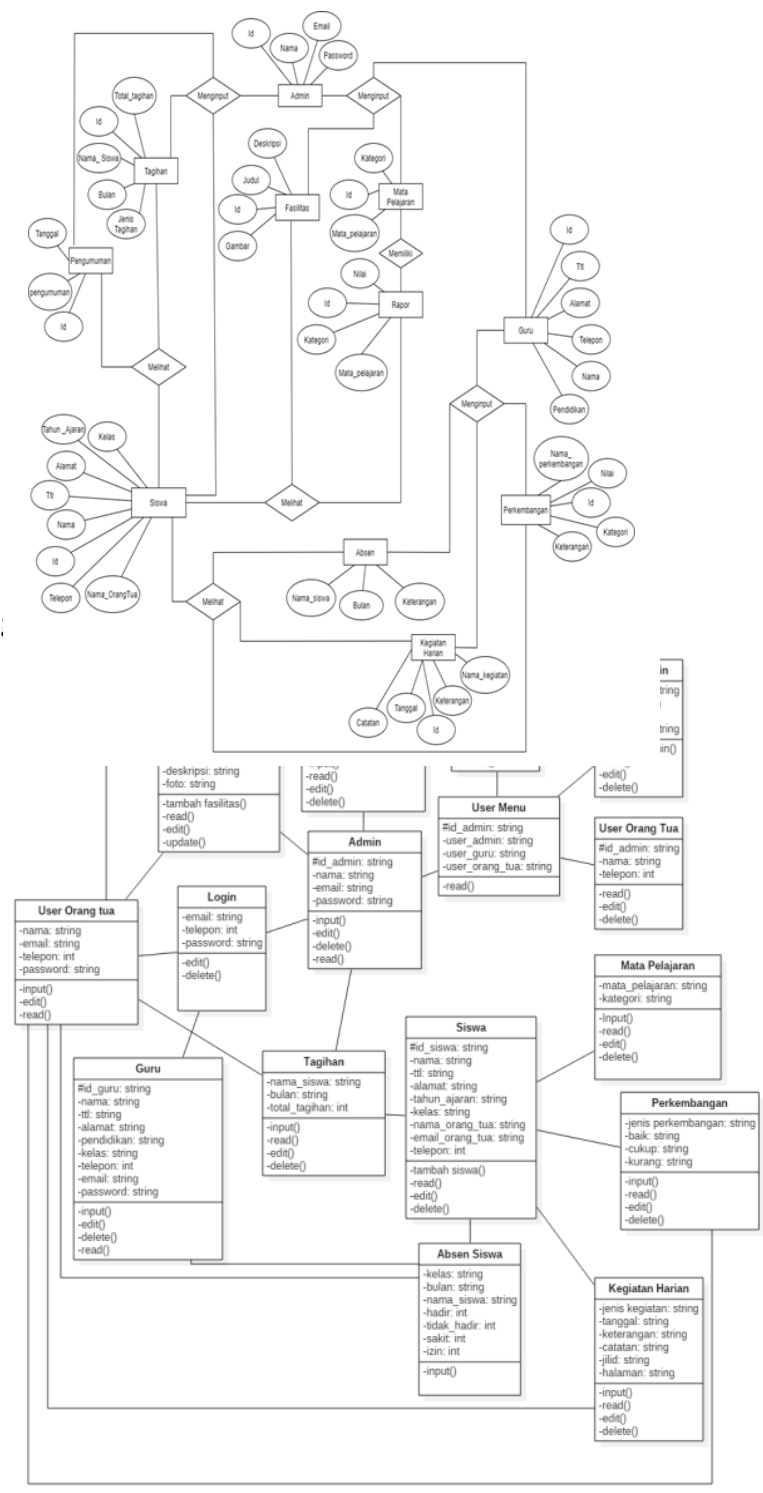

Gambar 9.Rancangan Class Diagram

\section{KESIMPULAN}

Berdasarkan hasil dari penulisan ini dapat disimpulkan bahwa: 1.Tercapainya pembuatan sistem informasi akademik ini dapat memberi kemudahan kepada pengelola TK Almadani untuk menyampaikan informasi lebih luas lagi dari sebelumnya.

2. Sistem informasi akademik ini dapat mempermudah pihak sekolah untuk mengelola data dan melaporkan hasil belajar siswa kepada orang tua siswa.

3. Dari hasil kuesioner uji coba aplikasi, mendapatkan ratarata persentase $84 \%$. Berarti aplikasi ini sudah layak digunakan dan dapat berjalan dengan efektif serta informasi yang disajikan dapat diterima dengan baik oleh pengguna.

\section{UCAPAN TERIMA KASIH}

Penulis menyampaikan terima kasih kepada orang-orang yang berhubungan denganpenelitian yang dibuat:

1) Kepada Allah Yang Maha Kuasa yang telah memberi kesempatan dalam kehidupan,kesehatan, rejeki dan pembelajaran.

2) Kepada segenap Pimpinan, Staff dan rekan dosen di lingkungan Universitas Muhammadiyah, Prof Dr. Hamka, Jakarta.

3) Kepada segenap Pimpinan, Dosen dan Staff Universitas Serang di Serang

4) Kepada segenap Staff LPPM Unsera di Serang

5) Kepada orangtua, saudara, sahabat dan rekan lainnya yang tidak dapat disebutkan satupersatu yang telah memberikan bantuan, semangat dan perhatian baik langsung maupuntidak langsung.

\section{REFERENSI}

[1] Andi, J. (2015). Pembangunan Aplikasi Child Tracker Berbasis Assisted - Global Positioning System ( A-GPS ) Dengan Platform Android. Jurnal Ilmiah Komputer Dan Informatika (KOMPUTA), 1(1), 1-8. elib.unikom.ac.id/download.php?id=300375

[2] Anggraini, A. R., \& Oliver, J. (2019). 済無 No Title No Title. Journal of Chemical Information and Modeling, 53(9), https://doi.org/10.1017/CBO9781107415324.004

[3] Cholifah, W. N., Yulianingsih, Y., \& Sagita, S. M. (2018). Pengujian Black Box Testing pada Aplikasi Action \& Strategy Berbasis Android dengan Teknologi Phonegap. STRING (Satuan Tulisan Riset Dan Inovasi Teknologi), 3(2), 206. https://doi.org/10.30998/string.v3i2.3048

[4] Eddy Handoko,Dede Kusnadi, A. U. (2019). Pengantar Sistem Administrasy. Journal of Chemical Information and Modeling, 53(9), $1689-1699$ https://doi.org/10.1017/CBO9781107415324.004 
[5] Herliana, R. (2017). Perancangan sistem informasi perkembangan belajar anak berbasis web pada taman kanak- kanak armia bandung skripsi. 1-18.

[6] IMADUDDIN, A. (2019). Sejarah Dan Perkembangan Kaligrafi. Journal of Chemical Information and Modeling, 53(9), 1689-1699. https://doi.org/10.1017/CBO9781107415324.004

Informasi, S. S., Teknik, F., \& Surabaya, U. N. (2019). PENDIDIKAN PENERBANGAN Kevin Andhika Ramadhan Ardhini Warih Utami Abstrak. 9, 136-143.

[7] Kasus, S., Sam, U., Pusparini, E. S., Najoan, M. E. I., Najoan, X. B. N., \& Elektro-ft, J. T. (2016). Sistem Informasi Akademik Berbasis Mobile Web Menggunakan Pendekatan Metodologi Rad (Studi Kasus: Universitas Sam Ratulangi). Jurnal Teknik Elektro Dan Komputer, 6(4),

$182-193$. https://doi.org/10.35793/jtek.6.4.2017.23232

[8] Kosidin, \& Farizah, R. N. (2016). Pemodelan Aplikasi Mobile Reminder Berbasis Android. Seminar Nasional Teknologi Informasi Dan Komunikasi 2016 (SENTIKA 2016), 2016(Sentika), 271-280.

[9] Mohammadi, S., Nikkhahan, B., \& Sohrabi, S. (2009). Challenges of User Involvement in Extreme Programming Projects. International Journal of Software Engineering and Its Applications (IJSEIA), 3(1), 19-32.

[10] Tofik Isa, I. G., \& Hartawan, G. P. (2017). Perancangan Aplikasi Koperasi Simpan Pinjam Berbasis Web. Ilmiah Ekonomi Vol. 5 Edisi 10, 5, 139-151.

[11] Yoga, P. I. P. A. (2015). Rancang Bangun Sistem Informasi Klinik Praktik Dokter Berbasis Web. Jurnal Teknologi Informasi Dan Komputer, 1, 127-133. 